\title{
Treatment Outcomes and Predictors Among Tuberculosis Patients at Madda Walabu University Goba Referral Hospital, Southeast Ethiopia
}

This article was published in the following Dove Press journal: Infection and Drug Resistance

\author{
Ayele Mamo (D) \\ Mohammedaman Mama $\mathbb{D}^{2}$ \\ Damtew Solomon ${ }^{3}$ \\ Mesud Mohammed' \\ 'Department of Pharmacy, School of \\ Medicine, Madda Walabu University \\ Goba Referral Hospital, Bale Goba, \\ Ethiopia; ${ }^{2}$ Department of Medical \\ Laboratory Science, School of Medicine, \\ Madda Walabu University Goba Referral \\ Hospital, Bale Goba, Ethiopia; \\ ${ }^{3}$ Department of Biomedical Science, \\ School of Medicine, Madda Walabu \\ University Goba Referral Hospital, Bale \\ Goba, Ethiopia
}

Background: Tuberculosis (TB) remains a main public health threat worldwide. Over $90 \%$ of tuberculosis cases occur in low- and middle-income countries that have fragile health infrastructures and constrained resources available. Ethiopia ranks third in Africa and eighth of 22 from TB burdened countries globally. Case detection as early as possible and ensuring a successful treatment rate should be the main focus points to decrease the burden of TB.

Objective: To evaluate tuberculosis treatment outcomes and predictors among tuberculosis treatment follow-up patients at Madda Walabu University Goba Referral Hospital.

Methods: Retrospective document review was conducted among TB patients in the tuberculosis clinic at Goba Referral Hospital from January 1, 2015 to December 30, 2019. Data were analyzed using SPSS version 25.0. Descriptive and logistic regressions analyses were performed to identify the rate and predictors of tuberculosis treatment outcomes. The odds ratio and $95 \%$ confidence interval were calculated to check the association between variables. $P \leq 0.05$ was considered statistically significant.

Results: The mean age of participants was $33.8 \pm 17.3$ years, and more than half of them $(58.4 \%, 218)$ were males. From the total 373 participants, $65(17.4 \%)$ registered TB patients were diagnosed HIV-positive. The overall success rate was $320(91.2 \%)$ with [95\% CI, 88-94.3]. Among these, 91 (25.9\%) were cured and 229 (65.2\%) completed treatment whereas $8.8 \%$ with [95\% CI, 5.7-12] were unsuccessful treatment outcomes. Among them, the majority $18(5.1 \%)$ died, $6(1.7 \%)$ were moved to MDR-TB center, $4(1.1 \%)$ were lost to follow-up and $3(0.9 \%)$ were documented as treatment failed.

Conclusion: The treatment failure rate was $8.8 \%$ with [95\% CI, 5.7-12]. The proportion of TB patents who died was relatively higher. HIV-positive patients and old age people were predictors of unsuccessful treatment outcomes. Thus, the health facility should strengthen the evaluation of HIV-positive patients and old age patients to minimize mortality.

Keywords: tuberculosis, treatment outcome, predictors, Madda Walabu University Goba Referral Hospital

\section{Introduction}

Tuberculosis (TB) remains a major public health problem worldwide and accounts for the highest mortality from any infectious diseases worldwide, even surpassing HIV/ AIDs, causing 1.5 million deaths in 2018. ${ }^{1,2}$ As of 2017, the global incidence of TB was estimated to be 10.0 million cases of which are 5.8 million men, 3.2 million women and 1.0 million children. Millions of people continue to fall sick with TB each year. For instance, in 2017, TB caused an estimated 1.3 million deaths accounting for $90 \%$ of adults aged $\geq 15$ years who were able to increase the productivity of the country ${ }^{3}$.
Correspondence: Ayele Mamo Department of Pharmacy, School of Medicine, Madda Walabu University Goba Referral Hospital, P. O. Box: 302, Bale Goba, Ethiopia

Email ayumam12@gmail.com 
China and India account for more than half of the TB burden worldwide. Sub-Saharan Africa, including Ethiopia, has the highest prevalence of TB infection in the world. In 2015, the WHO report showed that Ethiopia ranks third in Africa and eighth among the 22 highest TB burdened countries in the world. ${ }^{2}$ Ethiopia has achieved the $50 \%$ reduction of the millennium development goal related to TB. However, the decline of TB incidence and prevalence rate has been comparatively slow. Hence, the TB detection program and treatment success rate should be strengthened to achieve a sustainable development program target. ${ }^{4}$

An urgent response to a global epidemic highlights the need for immediate action to accelerate progress toward the goal of ending the TB epidemic by 2030 stating a $90 \%$ reduction in the absolute number of TB deaths and an $80 \%$ reduction in TB incidence compared with $2015 .^{5}$ Such levels have only been achieved in the context of aggressive treatment and follow-up while knowing the rate of treatment outcomes and predictors. A 2017 WHO report found that at least half of the world's population lack access to essential health services and almost $10 \%$ experience catastrophic expenditures on health. All of the 30 high TB burden countries including Ethiopia need to increase service coverage and reduce levels of catastrophic expenditures to reach the TB treatment goal and to make a healthy productive society. ${ }^{2}$

Increased diagnosis and treatment of $\mathrm{TB}$ infection remains crucial for eliminating $\mathrm{TB}^{6}{ }^{6}$ One of the big challenges not to achieve the TB treatment goal is nonadherence to medicine or to stop taking the medicine, which leads to poor treatment outcomes and infection of resistant TB. If bacteria show poor outcome for first line treatment, it may be harder to treat for a second time. Hence, it becomes drug resistant and that leads to unsuccessful treatment outcomes. This is to mean that regimens initially used to treat TB will no longer be able to fight the TB germs in the body due to different predictors. Multidrug resistant TB (MDR-TB) that is drug resistant to more than one drug is very dangerous and spreads the infection. $^{7}$

Poor treatment outcomes may be one of the factors to increase MDR-TB. Globally, 3.5\% of new TB cases and $18 \%$ of previously treated cases had MDR/RR-TB and $8.5 \%$ were estimated to have extensively drug resistant $\mathrm{TB}^{2}$ Of which 558,000 people developed TB that was resistant to rifampicin (RR-TB), which is the most effective first line drug and of these, $82 \%$ had MDR-TB. MDR-
TB continues to be a public health crisis especially in middle- and low-income countries.

Diagnosis and successful treatment of people with TB prevent millions of deaths each year (an estimated 54 million over the period 2000-2017), but there are still large and persistent gaps in detection and treatment. The latest treatment outcome data for new cases show a global treatment success rate of $82 \%$ in 2016 and $85 \%$ in 2017. This is a reduction from $86 \%$ in 2013 and $83 \%$ in $2015^{2,8}$

Ending the TB epidemic by 2035 requires rigorous efforts of the government, developmental partners, academicians, civic society organizations, patient advocates, private sector and the community at large. ${ }^{9}$ As a stakeholder of TB successful treatment outcomes, the goal achievement for the finding of this study is impute of national and WHO TB control policy. Ethiopia is one of the countries in the WHO list of 30 high TB burden that accounted for $87 \%$ of the world's cases with $150-400$ new TB cases. ${ }^{2}$

Case detection as early as possible and ensuring the treatment success rate are the main focus points to decrease the burden of TB. Understanding the treatment success rate and isolation of diverse predictors for treatment outcomes are essential to increase favorable tuberculosis treatment outcome. There is no study regarding treatment outcomes and predictors of unsuccessful treatment outcomes of TB in Southeast Ethiopia particularly in Bale Zone. Hence, the finding of this study is crucial for the study area as well as to national level to decrease the burden and predictors of poor treatment outcomes. Thus, this study aimed to evaluate the status and predictors of tuberculosis treatment outcomes.

\section{Methods and Materials Study Design, Study Area and Period}

A retrospective document review was conducted at Goba Referral Hospital. MWU-GRH (Madda Walabu University Goba Referral Hospital) is the largest teaching and referral hospital in Bale Zone. MWU-GRH is found in the southeast of Ethiopia, $445 \mathrm{~km}$ from the capital city of Addis Ababa. Goba Referral Hospital is the only referral hospital in Bale with a total of 166 clinical staff and 360 administrative workers. The hospital provides services for about 921,311 people annually in the areas of outpatient and inpatient service, emergency, laboratory, pharmacy, major and minor operations, neonatal intensive care, maternal and child health, ART service, physiotherapy, radiology 
and dermatology services. It is the center for TB treatment including MDR-TB care. TB patients' registration documents were reviewed from January 1, 2015 to December 30, 2019.

\section{Determination of Sample Size and Sampling Techniques}

All TB patients' records at MWU-GRH who started treatment and had complete medical records on TB treatment outcome in the past 5 years were included in the study.

\section{Data Abstraction Checklist and Processing}

A data abstraction checklist was designed based on both dependent and independent variables. Data were collected from the secondary source of the TB patients' registration $\log$ book. A structured data abstraction checklist was developed and used to extract all necessary information (Supplementary Material). Variables of interest were gender, age, weight, year of treatment, type of TB, HIV (human immunodeficiency virus) status and smear results as independent variables whereas dependent variables were treatment outcomes (successful and unsuccessful). The dependent variables were identified by evaluating tuberculosis treatment outcomes (cured, treatment completed, died, treatment failure, default treatment, moved to MDR-TB, transfer out and no record). Data were collected by two nurses with a bachelor degree and one pharmacist as supervisor. The data collectors were trained before the actual data collection for 2 days.

\section{Data Quality Management}

The principal investigator trained data collectors for 1 day about the objective and data abstraction procedure. For consistency, a $5 \%$ pre-test was conducted before the actual data at Bale Robe district hospital $15 \mathrm{~km}$ away from the study area to assess the validity of the data abstraction checklist. Based on this, the amendments and arrangements were made on the data abstraction checklist. The principal investigator also closely supervised the activity on a daily basis. At the end of each data gathering day, the principal investigator checked the completeness of filled questionnaires and whether recorded information makes sense to ensure the quality of data recorded. Data coding, cleaning and verification was done before entry into EPIdata. In addition to this, the principal investigator carefully entered and thoroughly cleared the data before commencement of the analysis.

\section{Data Analysis}

After collecting the data, data were organized and arranged categorically. Data for continuous variables were also presented by possible continuous measures of central tendency or variation or both. The data were entered into Epi-data version 4.0.2.101 and exported to Statistical Package for Social Sciences software (IBM SPSS statistics version 25, USA, 2017) for analysis. Descriptive statistics were determined including frequencies and percentages. The significant association between dependent and independent variables was checked by odds ratio with $95 \%$ confidence interval (CI). Binary and multivariate logistic regression model were used considering $p \leq 0.05$ statistically significant.

\section{Definitions of Outcome Terms}

The treatment outcome terms used in the current study were defined based on the Ethiopian standard guidelines. $^{10,11}$

\section{Cured Case}

A bacteriologically confirmed TB case that was smear or culture negative in the last month of treatment and on at least one previous occasion.

\section{Completed Treatment}

A patient who completed treatment but without evidence of failure but with no record to show that sputum or culture results in the last month of treatment and on at least on the previous occasion were negative, either because tests were not done or because results are unavailable.

\section{Failed Treatment}

TB cases with sputum smear or culture positive at the end of 5 months during treatment.

\section{Died}

A patient who had died during the course of TB treatment.

\section{Lost to Follow-Up}

A patient who has been on TB treatment for a minimum of 1 month and who interrupted his/her treatment for 2 months or more.

\section{Not Evaluated}

Patients with undetermined and for whom the final outcomes were not assessed. 


\section{Transferred Out}

Cases transferred out to another health facility or treatment unit.

\section{Moved to MDR-TB}

TB patients who were found to have RR-TB or MDR-TB before the fifth month of treatment and who were referred to MDR-TB unit and started on a full MDR-TB treatment regimen.

\section{Successful Treatment}

The number of cured patients plus treatment completed patients.

\section{Unsuccessful Treatment}

Include died, failure, moved to MDR-TB and lost to follow-up.

\section{Results}

\section{Baseline Characteristics of the Study}

\section{Participants}

As shown in Table 1, the total number of TB patients diagnosed and registered for TB treatment during the 5-year study period was 373. Among these, male sex has

Table I Baseline Characteristics of the Study Participants Attending the TB Clinic of Madda Walabu University Goba Referral Hospital from January, 2015 to December, 2019

\begin{tabular}{|l|l|l|l|}
\hline Variables & Category & $\begin{array}{l}\text { Frequency } \\
\text { (n) }\end{array}$ & $\begin{array}{l}\text { Proportion } \\
\text { (\%) }\end{array}$ \\
\hline Sex & Male & 218 & 58.4 \\
& Female & 155 & 41.6 \\
\hline Age category & $<18$ & 56 & 15.0 \\
& $18-25$ & 87 & 23.3 \\
& $25-35$ & 94 & 25.2 \\
& $35-50$ & 78 & 20.9 \\
& $>50$ & 58 & 15.5 \\
\hline Weight category at & $<20$ & 83 & 22.3 \\
start of treatment & $20-30$ & 122 & 32.7 \\
& $30-45$ & 89 & 23.9 \\
& $>45$ & 79 & 21.2 \\
\hline Address & Urban & 323 & 86.6 \\
& Rural & 50 & 13.4 \\
\hline Year of treatment & 2015 & 75 & 20.1 \\
& 2016 & 79 & 21.2 \\
& 2017 & 71 & 19.0 \\
& 2018 & 76 & 20.4 \\
& 2019 & 72 & 19.3 \\
\hline
\end{tabular}

shown dominance $(58.4 \%, 218)$ and the participants were $33.8 \pm 17.3$ years old while the weight of patients was 49.3 $\pm 13.4 \mathrm{~kg}$. The majority of the study participants $(86.6 \%$, 323) were residents of the urban area. Based on the year of treatment, the number of cases was minimum 71 and maximum 79 in the year 2017 and 2016 respectively, during the 5-year study period.

\section{TB Disease-Related Conditions of Patients}

Pulmonary tuberculosis (PTB) was observed in more than half $(55 \%, 205)$ of the study participants while the remaining $45 \%$ (168) of cases were extra pulmonary tuberculosis (ЕРTB). Out of the observed cases, the majority of them $(61.1 \%, 228)$ were smear negative, and 38.1\% (142) were found to be smear positive. During the 5 years, 65 (17.4) registered TB patients were diagnosed HIV-positive, of which 64 patients were initiated with CPT (cotrimoxazole preventive therapy). After 2 months of the initiation of TB treatment, the majority of the cases $(61.1 \%, 228)$ were found smear negative. Regarding the TB treatment, most of the patients $(97.9 \%, 365)$ received the standard RHZE (rifampicin, isoniazide, pyrazinamide, ethambutol) regimen during the 2 months of the intensive phase therapy, out of which 357 (95.7\%) of them were treated with $\mathrm{RH}$ standard regimen for the continuation phase therapy (Table 2).

\section{Tuberculosis Treatment Outcomes}

As shown in Table 3, out of 351 participants, 320 (91.2\%) with [95\% CI, 88-94.3] successfully completed TB treatment. Among these, 91 (25.9\%) were cured and 229 $(65.2 \%)$ completed whereas $8.8 \%$ with [95\% CI, 5.7-12] were unsuccessful treatment outcomes. Among them, the majority $18(5.1 \%)$ died, $6(1.7 \%)$ were moved to MDRTB center, $3(0.9 \%)$ were documented as treatment failed and $4(1.1 \%)$ were lost to follow-up. From the total 373 study participants, $12(3.2 \%)$ were transferred to other facilities and $10(2.7 \%)$ were not evaluated.

\section{Predictors of TB Treatment Outcomes}

To assess associated factors affecting treatment outcomes, all clinically relevant and variables that showed marginal association at $p<0.25$ following univariate analysis were included in the logistic regression analysis. Of those variables which fulfilled the inclusion criteria for the multivariate logistic regression analysis, only age of the patient as well as being HIV-positive had significant association with unsuccessful treatment outcomes. 
Table 2 TB Disease-Related Characteristics of the Study Participants Attending the TB Clinic of Madda Walabu University Goba Referral Hospital from January, 2015 to December, 2019

\begin{tabular}{|c|c|c|c|}
\hline Variables & Category & Frequency (n) & Proportion (\%) \\
\hline \multirow[t]{2}{*}{ Type of TB } & PTB & 205 & 55.0 \\
\hline & EPTB & 168 & 45.0 \\
\hline \multirow[t]{3}{*}{ Smear result } & Smear positive & 142 & 38.1 \\
\hline & Smear negative & 228 & 61.1 \\
\hline & Unknown & 3 & 0.8 \\
\hline \multirow[t]{3}{*}{ HIV status } & HIV-positive & 65 & 17.4 \\
\hline & HIV-negative & 296 & 79.4 \\
\hline & Unknown & 12 & 3.2 \\
\hline \multirow{3}{*}{$\begin{array}{l}\text { Cotrimoxazole } \\
\text { reventive } \\
\text { herapy initiated }\end{array}$} & Yes & 64 & 17.2 \\
\hline & No & 251 & 67.3 \\
\hline & Unknown & 58 & 15.5 \\
\hline \multirow{3}{*}{$\begin{array}{l}\text { Smear result } \\
\text { after } 2 \text { months }\end{array}$} & Smear positive & 17 & 4.6 \\
\hline & Smear negative & 267 & 71.6 \\
\hline & Unknown & 89 & 23.9 \\
\hline \multirow{2}{*}{$\begin{array}{l}\text { Anti-TB drug } \\
\text { on Intensive } \\
\text { phase }\end{array}$} & RHZE & 365 & 97.9 \\
\hline & RHZES & 8 & 2.1 \\
\hline \multirow{2}{*}{$\begin{array}{l}\text { Anti-TB drug } \\
\text { on continuation } \\
\text { phase }\end{array}$} & $\mathrm{RH}$ & 357 & 95.7 \\
\hline & $\mathrm{EH}$ & 16 & 4.3 \\
\hline
\end{tabular}

Abbreviations: PTB, pulmonary TB; RHZE, rifampicin, isoniazide, pyrazinamide, ethambutol; RHZES, rifampicin, isoniazide, pyrazinamide, ethambutol, streptomycin; $\mathrm{RH}$, rifampicin, isoniazide; $\mathrm{EH}$, ethambutol, isoniazide.

Accordingly, study participants who had an HIVpositive result were about five times more likely to have unsuccessful treatment outcomes $(\mathrm{AOR}=4.9 ; 95 \% \mathrm{CI}=$ 2.01-11.5, $P=0.000)$ relative to HIV-negative patients. On the other hand, patients with age greater than 40 years had a three times more unsuccessful treatment rate (AOR $=3.1 ; 95 \% \mathrm{CI}=1.1-8.1, P=0.021)$ relative to patients with age less than 25 years (Table 4).

\section{Discussion}

The magnitude of successful TB treatment outcomes was 91.2\% with [95\% CI, 88-94.3]. Among these, 91 (25.9\%) were cured and $229(65.2 \%)$ completed treatment while $8.8 \%$ with [95\% CI, 5.7-12] were unsuccessful treatment outcomes. From $8.8 \%$, the majority (5.1\%) died, $1.7 \%$ moved to MDR-TB center, $0.9 \%$ were documented as treatment failed and $1.1 \%$ were lost to follow-up. In logistic regression analysis, HIV-positive patients were about
Table 3 TB Treatment Outcomes-Related Characteristics of the Study Participants Attending the TB Clinic of Madda Walabu University Goba Referral Hospital from January, 2015 to December, 2019

\begin{tabular}{|c|c|c|c|}
\hline $\begin{array}{l}\text { Treatment } \\
\text { Outcomes }\end{array}$ & Category & $\begin{array}{l}\text { Frequency } \\
\text { (n) }\end{array}$ & Percentage \% \\
\hline $\begin{array}{l}\text { Successful } \\
\text { outcomes }\end{array}$ & $\begin{array}{l}\text { Cured } \\
\text { Completed } \\
\text { Died } \\
\text { Failure }\end{array}$ & $\begin{array}{l}91 \\
229 \\
18 \\
3\end{array}$ & $\begin{array}{l}25.9 \\
65.2 \\
5.1 \\
0.9\end{array}$ \\
\hline $\begin{array}{l}\text { Unsuccessful } \\
\text { outcomes }\end{array}$ & $\begin{array}{l}\text { Moved to } \\
\text { MDR-TB } \\
\text { Lost to } \\
\text { follow-up }\end{array}$ & $\begin{array}{l}6 \\
4\end{array}$ & $\begin{array}{l}1.7 \\
1.1\end{array}$ \\
\hline $\begin{array}{l}\text { Unknown final } \\
\text { status }\end{array}$ & $\begin{array}{l}\text { Transfer out } \\
\text { Not evaluated }\end{array}$ & $\begin{array}{l}12 \\
10\end{array}$ & $\begin{array}{l}3.2 \\
2.7\end{array}$ \\
\hline $\begin{array}{l}\text { Overall success } \\
\text { rate }\end{array}$ & $\begin{array}{l}\text { Successful } \\
\text { Unsuccessful }\end{array}$ & $\begin{array}{l}320 \\
31\end{array}$ & $\begin{array}{l}91.2[95 \% \mathrm{Cl} \text {, } \\
88-94.3] \\
8.8[95 \% \mathrm{Cl} \\
5.7-12]\end{array}$ \\
\hline
\end{tabular}

Abbreviation: $\mathrm{Cl}$, confidence interval.

five times more likely to have unsuccessful treatment outcomes $(\mathrm{AOR}=4.9 ; 95 \% \mathrm{CI}=2.01-11.5, P=0.000)$ relative to HIV-negative patients and patients with age greater than 40 years were three times more likely to have anunsuccessful treatment rate (AOR $=3.1 ; 95 \% \mathrm{CI}$ $=1.1-8.1, P=0.021)$ relative to patients with age less than 25 years.

According to the findings obtained by our study, $91.2 \%$ of participants had shown successful TB treatment outcomes. Of which, $25.9 \%$ were cured and $65.2 \%$ completed their treatment. The success rate in the current study was in line with the retrospective studies conducted in eastern Ethiopia, Harar with success rate of $92.5 \%,{ }^{12} 89.2 \%$ in Tigray, ${ }^{13}$ overall mean treatment success rate $92.4 \%$ in Hawassa, ${ }^{14} 89 \%$ in Sidama zone,${ }^{15}$ the Ethiopian national strategic goals $(90 \%)$ set for $2020^{11}$ and the WHO 2030 international target of $\geq 90 \%{ }^{8}$

The treatment success rate in our study $(91.2 \%)$ was higher than previous similar studies in Adama (80.8\%), ${ }^{16}$ retrospective studies in Addis Ababa 82.7\%, ${ }^{17}$ Hosanna $(43.3 \%),{ }^{18}$ Arba Minch (74.6\%), ${ }^{19} 86.1 \%$ in Amhara region, northern Shoa, ${ }^{20}$ a study from selected hospitals in Ethiopia $(55.8 \%)^{21}$ and the pooled estimate of TB treatment success rate in Ethiopia (86\%). ${ }^{22}$ The finding in this study is still higher than the finding from other countries with treatment success rate of $57.7 \%$ in 
Table 4 Multiple Logistic Regression of Predictors with TB Treatment Outcomes Among the Study Participants Attending the TB Clinic of Madda Walabu University Goba Referral Hospital from January, 2015 to December, 2019

\begin{tabular}{|c|c|c|c|c|c|}
\hline Variables & Category & COR $(95 \% \mathrm{Cl})$ & $P$ value & AOR $(95 \% \mathrm{Cl})$ & $P$ value \\
\hline Age & $\begin{array}{l}\text { Age }<25 \\
25-40 \\
>40\end{array}$ & $\begin{array}{l}1.3(0.4-3.7) \\
3.4(1.3-8.6)\end{array}$ & $\begin{array}{l}1.000 \\
0.614 \\
0.009 *\end{array}$ & $\begin{array}{l}0.8(0.2-2.6) \\
3.1(1.1-8.1)\end{array}$ & $\begin{array}{l}1.000 \\
0.825 \\
0.021^{* *}\end{array}$ \\
\hline Year of treatment & $\begin{array}{l}2015 \\
2016 \\
2017 \\
2018 \\
2019\end{array}$ & $\begin{array}{l}0.8(0.2-2.8) \\
1.2(0.4-3.8) \\
1.4(0.4-4.2) \\
0.2(0.0-1.4)\end{array}$ & $\begin{array}{l}0.753 \\
0.654 \\
0.523 \\
0.129 \\
1.000\end{array}$ & $\begin{array}{l}0.7(0.1-2.6) \\
\text { I.I }(0.3-3.5) \\
\text { I.I }(0.3-3.6) \\
0.2(0 . I-I .5)\end{array}$ & $\begin{array}{l}0.630 \\
0.821 \\
0.827 \\
0.146 \\
1.000\end{array}$ \\
\hline HIV status & $\begin{array}{l}\text { HIV-positive } \\
\text { Unknown } \\
\text { HIV-negative }\end{array}$ & $\begin{array}{l}4.8(2.2-10.6) \\
1.4(0.1-12.2)\end{array}$ & $\begin{array}{l}0.000 * \\
0.711 \\
1.000\end{array}$ & $\begin{array}{l}4.9(2.0 \mathrm{I}-\mathrm{II} .5) \\
\mathrm{I} .4(0.1-12.8)\end{array}$ & $\begin{array}{l}0.000 * * \\
0.757 \\
1.000\end{array}$ \\
\hline
\end{tabular}

Notes: *Statically significant in bivariate; **statistically significant in multivariate.

Abbreviations: $\mathrm{AOR}$, adjusted odds ratio; $\mathrm{Cl}$, confidence interval; $\mathrm{COR}$, crude odds ratio; HIV, human immunodeficiency virus.

Nigeria, ${ }^{23} 81 \%$ in northern Tanzania, ${ }^{24} 77.4 \%$ in Yemen, ${ }^{25}$ $53.4 \%$ in Malaysia ${ }^{26}$ and $80.5 \%$ in Denmark ${ }^{27}$ and a study from China by Bao et al with $88 \%{ }^{28}$ The difference may be due to the sample size used in the study, geographical difference, study period, study population and setting difference, for example the study in Tanzania was done in 2007 and a community-based study. The study in Nigeria by Ukwaja et al in 2013 included transferred out patients to unsuccessful treatment outcomes. ${ }^{23}$

The magnitude of successful treatment outcomes of our study is lower than Endris et al's study in Gojam, Northwest Ethiopia with $94.8 \%$ successful treatment outcome, ${ }^{29}$ and Ahmed et al's study in Pakistan with success rate of $94.9 \% .^{30}$ The differences between treatment success rates might be due to geographical variation of study settings, sample size difference and variation of the study periods. Another possible explanation could be also due to the variation in the implementation of TB treatment strategies.

In terms of unsuccessful TB treatment outcomes in this study, overall $8.8 \%$ with [95\% CI, 5.7-12] TB patients did not successfully complete their treatments. Among them, 5.1\% died, $1.7 \%$ moved to MDR-TB center, $0.9 \%$ were documented as treatment failure and $1.1 \%$ were lost to follow-up.

From the point of view of the death rate, $5.1 \%$ of cases died according to the current study. This was lower than the mortality rate among all TB patients of similar studies conducted in the northern part of Ethiopia (Gondar, 17.7\%), southwestern Nigeria (11.5\%) and Yemen $(12.2 \%){ }^{25,31,32}$ The difference in mortality rate seen could be due to variation of the year of study in which case the improvement of the healthcare system could be implicated, type of study population, variation of the sample size and possibly the variation in epidemiological entities associated with geographical locations. For example, the sample size of the study conducted by Babatunde et al (78 cases) $)^{32}$ was much lower than our study (373 cases), and that of the study conducted by Biruk et al in Gondar Teaching Hospital (1584 cases) ${ }^{31}$ was much higher than our study sample size. In addition, their study included only pulmonary TB cases while the current study constituted both PTB and EPTB cases. On the other hand, non-adherence to TB treatment strategies and program implementation could be the other possible explanation for mortality rate variations.

On the contrary, the mortality rate of our study was comparatively close to different studies from other regions in the country with $5 \%$ in Adama, ${ }^{16} 5.6 \%$ in Debre Tabor, ${ }^{33} 2.9 \%$ in Tigray region, ${ }^{13} 1.8 \%$ in Arba Minch, ${ }^{19}$ $3.7 \%$ in Addis Ababa, ${ }^{34} 3.9 \%$ in $\mathrm{Harar}^{12}$ and $3.8 \%$ in northern Shoa $^{20}$ and elsewhere in China $(2.8 \%)^{28}$ and Pakistan (1.8\%). ${ }^{30}$ However, our study finding is much lower than the mortality rate $(19.4 \%)$ of the study done in Nigeria. ${ }^{23}$ This could be due to difference in study population and the increased awareness and health education for the patients regarding the benefit of treatment adherences and improvements and changes in healthcare services provisions in our settings.

The magnitude of tuberculosis lost to follow-up treatment outcomes for TB patients who had undergone diagnosis and registration for treatment during the 5-year study period was $1.1 \%$. The finding is almost parallel to similar studies conducted in Sidama with $1 \%$ in the year 2012, ${ }^{15}$ 
in Hawassa $2.6 \%{ }^{14}$ and $2.4 \%$ in Harar. ${ }^{12}$ Nonetheless, our finding of the lost to follow-up rate was less than the study finding $(11.1 \%)$ in Dilla, southern Ethiopia. ${ }^{35}$ The variation could be explained by the difference in the study period which was from 2008 to 2013 and the large sample size used (1537) in the study at Dilla hospital.

The other important denominator of unsuccessful treatment outcomes in TB patients is treatment failure. In the current study, the proportion of treatment failure documented was $0.9 \%$. This finding is consistent with other retrospective studies from Ethiopia with a treatment failure rate of $0.6 \%$ in Addis Ababa, ${ }^{34} 0.8 \%$ in Gondar, ${ }^{31} 0.5 \%$ in Tigray ${ }^{13}$ and $0.6 \%$ in Arba Minch. ${ }^{19}$ Nonetheless, the rate of treatment failure of the current research is slightly superior to other research findings done in northern $(0.3 \%)^{36}$ parts of Ethiopia, and similar studies from Zambia $(0.3 \%)^{37}$ and Pakistan $(0.2 \%){ }^{30}$ Ccontrary to this, our treatment failure rate finding is lower than other similar studies, Melese and Ewnete $3.5 \%{ }^{33}$ and Tesema et al $1.4 \%{ }^{16}$ in Ethiopia and $8.3 \%$ in southern Nigeria. ${ }^{32}$

In an attempt to assess predictors of treatment outcomes, being HIV-positive as well as old age had significant association with unsuccessful treatment outcomes. Accordingly, participants who had HIV-positive were about five times more likely to have unsuccessful treatment outcomes $(\mathrm{AOR}=4.9 ; 95 \% \mathrm{CI}=2.01-11.5, P=$ $0.000)$ relative to HIV-negative patients. The finding is similar to the study at Woldia General Hospital, northeast part of Ethiopia, where HIV-negative tuberculosis patients were 3.9 times more likely to have a successful treatment outcome than HIV-positive tuberculosis patients. ${ }^{38}$ This might be explained by the fact that those patients who adhered well to their directly observed treatments during the intensive phase therapy have an increased likelihood of cure and successful treatment which can be expressed in terms of smear negativity. On the other hand, patients with age greater than 40 years had three times more unsuccessful treatment rate $(\mathrm{AOR}=3.1 ; 95 \% \mathrm{CI}=1.1-8.1, P=$ $0.021)$ relative to patients with age less than 25 years. The result is supported by the TB treatment outcomes study at Woldia in which those with age less than 24 years were 4.7 times more likely to have successful treatment outcomes than those with age greater than 45 years. ${ }^{38}$ On the other hand, in the study in Tigray by Berhe et $\mathrm{al},{ }^{13}$ the odds of unsuccessful treatment outcome was 2.5 times higher among patients older than 40 years of age. Similarly, according to the study by Tola et al, older age was significantly associated with unsuccessful TB treatment outcomes. ${ }^{12}$ Despite the fact that TB affects all age groups, as compared to younger age group, most cases (90\%) in the 2016 global tuberculosis report were adults. ${ }^{5}$

\section{Limitation of the Study}

Since the data were collected from document review retrospectively, there was some incomplete information and they were unable to include other key important variables like adherence measure. The study was conducted in a single health facility. The researchers recommend a further prospective TB patients' follow-up study with multicenter facilities to fill the limitation of this study.

\section{Conclusion}

The magnitude of treatment success rate of the study was $91.2 \%$ and unsuccessful treatment outcomes were $8.8 \%$. HIVpositive patients relative to HIV-negative patients and old age patients relative to younger age patients were predictors of unsuccessful treatment outcomes. The proportions of died TB patients and lost to follow-up TB patients were relatively higher. Thus, the health facility should strengthen the followup of HIV-positive and old age patients to minimize mortality and overall unsuccessful treatment outcomes.

\section{Abbreviations}

EPTB, extra pulmonary tuberculosis; HIV, human immunodeficiency virus; MDR, multidrug resistant; MWU-GRH, Madda Walabu University Goba Referral Hospital; PTB, pulmonary TB; RH, rifampicin, isoniazide; RHZE, rifampicin, isoniazide, pyrazinamide, ethambutol; RR-TB, rifampicin resistant tuberculosis; SPSS, Statistical Package for Social Science; TB, tuberculosis; WHO, World Health Organization.

\section{Data Sharing Statement}

The datasets used and analyzed throughout the current study are obtainable from the corresponding author on reasonable request.

\section{Ethical Consideration}

Ethical permission was achieved from the MWU-MWU ethical review committee. Letter of cooperation was written to MWU-GRH. Since we reviewed secondary data no need of informed consent from the patient but written informed consent was taken from the clinical director. Strict confidentiality was maintained during data collection process as well as secrecy was kept during data processing and report writing. The study was also conducted in accordance with the Helsinki Declaration. 


\section{Acknowledgment}

We want to express our great thanks to MWU-GRH TB clinic staff for their support. We would like to extend our appreciation for people working with us.

\section{Author Contributions}

All authors made substantial contributions to conception and design, acquisition of data, analysis and interpretation of data; took part in drafting the article and revising it critically for important intellectual content; agreed to submit to the current journal; gave final approval of the version to be published; and agree to be accountable for all aspects of the work.

\section{Funding}

The author not received funding from any organizations.

\section{Disclosure}

The authors declared that they have no competing interest.

\section{References}

1. Harding E. WHO global progress report on tuberculosis elimination. Lancet Respir Med. 2020;8(1):19. doi:10.1016/S2213-2600(19) 30418-7

2. WHO. Global tuberculosis 2018 report - World Health Organization. 2018. Available from: https://apps.who.int>iris $>b i t s t r e a m>h a n$ dle`9789241565646-eng. Accessed December 14, 2020.

3. Organization WH. WHO Guidelines on Tuberculosis Infection Prevention and Control: 2019 Update. World Health Organization;2019.

4. MOH/AS. Analytical summary - tuberculosis. 2019. Available from: http://www.aho.afro.who.int/profiles_information/index.php/ Ethiopia:Analytical_summary_-_Tuberculosis. Accessed December 14, 2020.

5. Floyd K, Glaziou P, Zumla A, Raviglione M. The global tuberculosis epidemic and progress in care, prevention, and research: an overview in year 3 of the end TB era. Lancet Respir Med. 2018;6(4):299-314. doi:10.1016/S2213-2600(18)30057-2

6. MacNeil A, Glaziou P, Sismanidis C, Date A, Maloney S, Floyd K. Global epidemiology of tuberculosis and progress toward meeting global targets - worldwide, 2018. MMWR Morb Mortal Wkly Rep. 2020;69(11):281-285. doi:10.15585/mmwr.mm6911a2

7. ALDA. American lung disease association. 2019. Available from: https://www.lung.org/lung-health-and-diseases/lung-disease-lookup /tuberculosis/diagnosing-and-treating-tuberculosis.html. Accessed December 14, 2020.

8. WHO. Global Tuberculosis 2019 Report - World Health Organization. 2019.

9. EEFT. Ethiopia's effort in fighting against tuberculosis is progressing, Availbale from: https://reliefweb.int/report/ethiopia/ethiopia-s-effortfighting-against-tuberculosis-tb-progressing-tb-still-predominates. Accessed December 14, 2020. 2019.

10. FMOH. Guidelines for Clinical and Programmatic Management of TB, TB/HIV and Leprosy in Ethiopia. 2016.

11. FMOH. Guidelines for Clinical and Programmatic Management of TB, TB/HIV and Leprosy in Ethiopia 6ed2018 Augest. 2018.
12. Tola A, Minshore KM, Ayele Y, Mekuria AN. Tuberculosis treatment outcomes and associated factors among TB patients attending public hospitals in Harar Town, Eastern Ethiopia: a Five-Year Retrospective Study. Tuberc Res Treat. 2019;2019:1503219.

13. Berhe G, Enquselassie F, Aseffa A. Treatment outcome of smear-positive pulmonary tuberculosis patients in Tigray Region, Northern Ethiopia. BMC Public Health. 2012;12(1):537. doi:10.11 86/1471-2458-12-537

14. Tsegaye B, Bedewi Z, Asnake SL. Treatment outcome of tuberculosis patients at adare general Hospital, Hawassa, Southern Ethiopia. (A five year retrospective study). 2019.

15. Dangisso MH, Datiko DG, Lindtjørn B, Dowdy DW. Trends of tuberculosis case notification and treatment outcomes in the Sidama Zone, southern Ethiopia: ten-year retrospective trend analysis in urban-rural settings. PLoS One. 2014;9(12):e114225. doi:10.1371/ journal.pone. 0114225

16. Tesema T, Seyoum D, Ejeta E, Tsegaye R. Determinants of tuberculosis treatment outcome under directly observed treatment short courses in Adama City, Ethiopia. PLoS One. 2020;15(4): e0232468.

17. Getahun B, Ameni G, Medhin G, Biadgilign S. Treatment outcome of tuberculosis patients under directly observed treatment in Addis Ababa, Ethiopia. Braz J Infect Dis. 2013;17(5):521-528. doi:10.10 16/j.bjid.2012.12.010

18. Mohammed T, Daniel K, Helamo D, Leta T. Treatment outcomes of tuberculosis patients in nigist Eleni Mohammed general hospital, hosanna, southern nations, nationalities and peoples region, Ethiopia: a five year (June 2009 to August 2014) retrospective study. Arch Public Health. 2017;75(1):16. doi:10.1186/s13690-0170184-x

19. Ifa AC. Human immunodeficiency virus as a determinant of tuberculosis treatment outcome in tuberculosis patients treated at Arba Minch General Hospital: a five-year retrospective study. HIV/AIDS Rev. 2018;17(2):74-80. doi:10.5114/hivar.2018.76376

20. Hailemeskel S, Mohammed OY, Ahmed AM. Retrospective assessment of the status and determinants of tuberculosis treatment outcome among patients treated in government hospitals in North Shoa Administrative Zone, Amhara Regional State, Ethiopia. Res Rep Trop Med. 2017;8:65-71.

21. Taye G, Defar A, Taddele T, et al. Treatment outcome and associated factors among TB patients in Ethiopia: Hospital-Based Retrospective Study. Am J Epidemiol Infect Dis. 2018;6(1):14-19. doi:10.12691/ ajeid-6-1-3

22. Seid MA, Ayalew MB, Muche EA, Gebreyohannes EA, Abegaz TM. Drug-susceptible tuberculosis treatment success and associated factors in Ethiopia from 2005 to 2017: a systematic review and meta-analysis. BMJ Open. 2018;8(9):e022111. doi:10.1136/bmjopen-2018-022111

23. Ukwaja K, Ifebunandu N, Osakwe P, Alobu I. Tuberculosis treatment outcome and its determinants in a tertiary care setting in south-eastern Nigeria. Niger Postgrad Med J. 2013;20(2):125-129.

24. van den Boogaard J, Lyimo R, Irongo CF, et al. Community vs. facility-based directly observed treatment for tuberculosis in Tanzania's Kilimanjaro Region. Int J Tuberc Lung Dis. 2009;13 (12):1524-1529.

25. Jaber AAS, Ibrahim B. Evaluation of risk factors associated with drug-resistant tuberculosis in Yemen: data from centres with high drug resistance. BMC Infect Dis. 2019;19(1):464. doi:10.1186/ s12879-019-4069-1

26. Ismail I, Bulgiba A. Determinants of unsuccessful tuberculosis treatment outcomes in Malaysian HIV-infected patients. Prev Med. 2013;57:S27-S30. doi:10.1016/j.ypmed.2012.12.023

27. Holden IK, Lillebaek T, Seersholm N, Andersen PH, Wejse C, Johansen IS. Predictors for pulmonary tuberculosis treatment outcome in Denmark 2009-2014. Sci Rep. 2019;9(1):12995. doi:10. 1038/s41598-019-49439-9 
28. Bao QS, Du YH, Lu CY. Treatment outcome of new pulmonary tuberculosis in Guangzhou, China 1993-2002: a register-based cohort study. BMC Public Health. 2007;7:344.

29. Endris M, Moges F, Belyhun Y, Woldehana E, Esmael A, Unakal C. Treatment outcome of tuberculosis patients at Enfraz Health Center, Northwest Ethiopia: a five-year retrospective study. Tuberc Res Treat. 2014;2014.

30. Ahmad T, Haroon KM, Khan MM, et al. Treatment outcome of tuberculosis patients under directly observed treatment short course and its determinants in Shangla, Khyber-Pakhtunkhwa, Pakistan: a retrospective study. Int $J$ Mycobacteriol. 2017;6 (4):360-364.

31. Biruk MYB, Yimam B, Abrha H, Biruk S, Amdie FZ. Treatment outcomes of tuberculosis and associated factors in an Ethiopian University Hospital. Adv Public Health. 2016;2016:1-9. doi:10. $1155 / 2016 / 8504629$

32. Babatunde OAEO, Ayodele M, Fadare JO, Isinjaye AO, Ibirongbe DO, Akinyandenu J. Factors affecting treatment outcomes of tuberculosis in a tertiary health center in Southwestern Nigeria. Int Rev Soc Sci Humanit. 2013;4(2):209-218.

33. Melese AZB, Ewnete B. Treatment outcome and associated factors among tuberculosis patients in Debre Tabor, Northwestern Ethiopia: a retrospective study. Tuberc Res Treat. 2016;2016.
34. Fentie AM, Jorgi T, Assefa T. Tuberculosis treatment outcome among patients treated in public primary healthcare facility, Addis Ababa, Ethiopia: a retrospective study. Arch Public Health. 2020;78(1):12. doi:10.1186/s13690-020-0393-6

35. Gebrezgabiher G, Romha G, Ejeta E, Asebe G, Zemene E, Ameni G. Treatment outcome of tuberculosis patients under directly observed treatment short course and factors affecting outcome in southern Ethiopia: a five-year retrospective study. PLoS One. 2016;11(2): e0150560. doi:10.1371/journal.pone.0150560

36. Abdulkader $M$, van Aken I, Niguse $S$, Hailekiros $H$, Spigt $M$. Treatment outcomes and their trend among tuberculosis patients treated at peripheral health settings of Northern Ethiopia between 2009 and 2014: a registry-based retrospective analysis. BMC Res Notes. 2019;12(1):786. doi:10.1186/s13104-019-4824-9

37. Nanzaluka FH, Chibuye S, Kasapo CC, et al. Factors associated with unfavourable tuberculosis treatment outcomes in Lusaka, Zambia, 2015: a secondary analysis of routine surveillance data. Pan Afr Med J. 2019;32:159. doi:10.11604/pamj.2019.32.159.18472

38. Getie A, Alemnew B. Tuberculosis treatment outcomes and associated factors among patients treated at Woldia General Hospital in Northeast Ethiopia: an Institution-Based Cross-Sectional Study. Infect Drug Resist. 2020;13:3423. doi:10.2147/IDR.S275568
Infection and Drug Resistance

\section{Publish your work in this journal}

Infection and Drug Resistance is an international, peer-reviewed openaccess journal that focuses on the optimal treatment of infection (bacterial, fungal and viral) and the development and institution of preventive strategies to minimize the development and spread of resistance. The journal is specifically concerned with the epidemiology of

\section{Dovepress}

antibiotic resistance and the mechanisms of resistance development and diffusion in both hospitals and the community. The manuscript management system is completely online and includes a very quick and fair peerreview system, which is all easy to use. Visit http://www.dovepress.com/ testimonials.php to read real quotes from published authors. 